Full length article

\title{
Mechanism of stress relaxation and phase transformation in additively manufactured Ti-6Al-4V via in situ high temperature XRD and TEM analyses
}

\author{
F.R. Kaschel ${ }^{\mathrm{a}, *}$, R.K. Vijayaraghavan ${ }^{\mathrm{b}}$, A. Shmeliov ${ }^{\mathrm{c}}$, E.K. McCarthyc ${ }^{\mathrm{c}}$, M. Canavan ${ }^{\mathrm{c}}$, P.J. McNally ${ }^{\mathrm{b}}$, \\ D.P. Dowling ${ }^{\mathrm{a}}$, V. Nicolosi ${ }^{\mathrm{c}}$, M. Celikin ${ }^{\mathrm{a}, *}$ \\ ${ }^{a}$ School of Mechanical \&' Materials Engineering, University College Dublin, Belfield, Dublin 4, Ireland \\ ${ }^{\mathrm{b}}$ School of Electronic Engineering, Dublin City University, Glasnevin, Dublin 9, Ireland \\ ${ }^{\mathrm{c}}$ School of Chemistry and CRANN, Naughton Institute, Trinity College Dublin, Dublin 2, Ireland
}

\section{A R T I C L E I N F O}

\section{Article History:}

Received 28 September 2019

Revised 9 February 2020

Accepted 23 February 2020

Available online 27 February 2020

\section{Keywords:}

Additive manufacturing

Ti-6Al-4V

In situ

High temperature transmission electron

microscopy

High temperature X-ray diffraction

Phase transformation

Stress relaxation

\begin{abstract}
A B S T R A C T
Additive manufacturing is being increasingly used in the fabrication of Ti-6Al-4V parts to combine excellent mechanical properties and biocompatibility with high precision. Unfortunately, due to the build-up of thermal residual stresses and the formation of martensitic structure across a wide range of typical processing conditions, it is generally necessary to use a post-thermal treatment to achieve superior mechanical performance. This investigation aims to obtain a deeper understanding of the micro/nanostructural evolution ( $\alpha^{\prime}$ martensite phase decomposition), accounting for the kinetics of phase transformation during the heat treatment of 3D-printed Ti-6Al-4V alloy. As the mechanism of phase transformation and stress relaxation is still ambiguous, in this study the changes in crystal lattice, phase, composition and lattice strain were investigated up to $1000^{\circ} \mathrm{C}$ using both in situ high temperature X-ray diffraction (XRD) and transmission electron microscopy (TEM). Based on the result a mechanism of phase transformation is proposed, via the accommodation/substitution of $\mathrm{Al}, \mathrm{V}$ and Ti atoms in the crystal lattice. The proposed mechanism is supported based on elemental concentration changes during heat treatment, in combination with changes in crystal structure observed using the high temperature XRD and TEM measurements. This study provides a deeper understanding on the mechanism of phase transformation through martensitic decomposition, as well as a deeper understanding of the influence of post-thermal treatment conditions on the alloy's crystal structure.
\end{abstract}

(c) 2020 Acta Materialia Inc. Published by Elsevier Ltd. All rights reserved.

\section{Introduction}

Additive manufacturing (AM) has become increasingly important in the aeronautical, medical device and automotive sectors, due to its ability to produce consolidated parts for specific end-use applications [1]. Titanium and its alloy Ti-6Al-4V (Ti64) are the preferred materials in the AM production due to their corrosion resistance, biocompatibility, high specific strength, superior mechanical properties and fracture toughness [2]. Furthermore, the mechanical performance of AM processed Ti64 is equivalent if not better compared to Ti64 components produced with traditional routes [3]. In AM processes, distinctively laser-based systems, melted layers experience extremely high cooling rates $\left(\sim 10^{3}-10^{8} \mathrm{~K} / \mathrm{s}\right)$, which lead to the formation of metastable acicular martensitic phase with hexagonal close packed (HCP) crystal structure, whereas conventional processing $(\sim 0.5 \mathrm{~K} / \mathrm{s})$ yields

\footnotetext{
* Corresponding authors.

E-mail addresses: frederico.rossi@i-form.ie (F.R. Kaschel), mert.celikin@ucd.ie (M. Celikin).
}

typical $\alpha+\beta$ (equilibrium) microstructure exhibiting excellent fatigue performance [4-6]. In addition, thermal cycling occurs by successive layer deposition and melting during additive manufacturing which results in the formation of residual stresses. Liu Y et al. reported that during deposition of a new layer on the previously scanned layers, compressive stress increases within the underlying layers due to thermal cycling while tensile stress within the top layer is converted into compressive stress [7]. As a result, extensive research has been carried out in an attempt to optimise the as-fabricated parts to reduce and/or eliminate residual stresses through tailoring AM process parameters [8-13]. Haider et al., for example, determined that residual stresses can be reduced by optimising parameters such as laser power, scan speed and scan pattern, whereby the cooling rate and temperature gradient is lowered [9].

A second common method used to address some of the fabrication limitations is through the post-processing treatment of parts. Hot isostatic pressing (HIP) and heat treatment (Annealing) are two methods used in the industry to enhance the performance of AM fabricated parts [14]. The improved properties are achieved by inducing 
microstructural changes during heat treatment, more specifically, grain growth. This growth can be controlled through the tailoring of the thermal arrest period and heating rates. For example, it was observed that by using a heating rate of $3.3^{\circ} \mathrm{C} / \mathrm{min}$ and $10^{\circ} \mathrm{C} / \mathrm{min}$, resulted in a net grain growth of $0.49 \%$ and $0.32 \%$, respectively, after annealing for $1 \mathrm{~h}$ at $1015^{\circ} \mathrm{C}$ [14]. HIP has become the preferred method for the closure of internal pores in both cast and AM produced parts. The process is conducted on chemically clean components, in a heated, argon-filled pressure vessel, usually at pressures of 69 to $103 \mathrm{MPa}(10-15 \mathrm{ksi})$ between $900-955^{\circ} \mathrm{C}$ achieved using a heating rate of $5^{\circ} \mathrm{C} / \mathrm{min}[14,15]$. However, due to the high cost associated with HIP, optimised as-built parts with low porosity are commonly heat treated. The standard industrial aeronautical postthermal treatment is based on DIN 17869, which states that stress relief heat treatment is recommended for component manufacturing using multi-layered weld seams. The process parameters are based on indications of DIN 65083 for thermal treatment of cast components made of titanium and titanium alloys for aerospace $[15,16]$. Uhlmann et al. for example investigated the effect of thermal treatment on the microstructure of printed parts under protective gas using a heating rate of $5^{\circ} \mathrm{C} / \mathrm{min}$, holding period of $60 \mathrm{~min}$ at $675^{\circ} \mathrm{C}$ followed by inert gas cooling based on these standards to [17].

As additive manufacturing has gained considerable industrial interest, the need to optimise the process has resulted in several studies focused on determining the optimal annealing strategy to relieve internal residual stresses and achieve tailored phase composition with application specific mechanical properties. Elmer et al. [18], for example, observed a lattice contraction of $0.57 \%$ after annealing for $2 \mathrm{~h}$ at $450^{\circ} \mathrm{C}$, while Combres [19] observed complete relaxation after annealing at $730^{\circ} \mathrm{C}$ for $2 \mathrm{~h}$. Vracken et al. reported that the fine martensitic structure was fully transformed to a mixture of $\alpha$ and $\beta$ after heat treatment of $2 \mathrm{~h}$ at $780^{\circ} \mathrm{C}$, with the $\alpha$ phase present as fine needles [20]. Vilaro et al. examined the effect of conventional and optimized heat treatments on the mechanical behaviour of parts. In their studies it was observed that the gradual decomposition of $\alpha^{\prime}$, achieved by annealing at $850^{\circ} \mathrm{C}$ for $2 \mathrm{~h}$ followed by air cooling, produced an increase in hardness in comparison to annealing at lower temperatures [21]. Coincidently, Zhang et al. reported an improvement in ductility after heat treatment at a temperature range of $850-900^{\circ} \mathrm{C}$ for $2 \mathrm{~h}$ followed by furnace cooling due to the full decomposition of $\alpha^{\prime}$ [13]. In contrast, Ter Haar and Becker [22] claim that superior tensile properties are achieved by duplex annealing (part held at $950^{\circ} \mathrm{C}$ for $4 \mathrm{~h}$, followed by water quenching), resulting in bi-modal microstructure when compared to standard annealing strategies. Evidently, most investigations focus on understanding the effect of varying heat treatment cycles on the mechanical performance based on the final part microstructure. Therefore, a deeper understanding of the micro/nanostructural evolution ( $\alpha^{\prime}$ martensite phase decomposition) accounting for the kinetics of phase transformation is critical, in order to optimise heat treatment procedures applied on 3D-Printed Ti-6Al-4V alloy. In 2002 Pederson used high temperature X-ray diffraction (HT-XRD) to study the phase transformation kinetics in cast Ti64 during heating up, isothermal hold and cooling down. In his studies, the thermal expansion behaviour was examined based on changes in both phase fraction and $d$-spacings [23]. Equivalently, in this study the processing conditions used for in situ characterisation are representative of that commonly used in industry for the additive manufacturing of Ti64 alloy.

Martensitic $\alpha^{\prime}$ is conveniently viewed as a distorted $\alpha$-hcp structure with smaller lattice parameters $(a=2.931 ; c=4.681 \AA$, with $c / a=1.597)[24]$. A recent study revealed that after work hardening, equilibrium $\alpha$ and martensitic $\alpha^{\prime}$ phases can coexist as dual-phase $\alpha+$ $\alpha^{\prime}$ microstructure in a matrix of $(\alpha+\beta)$ lamellar [25]. It has been reported that during heat treatment, diffusion of aluminium (Al), vanadium (V) and titanium (Ti) occurs as the microstructure changes [26-29]. Matsumoto et al. proposed that during solution treatment, V enrichment occurs as $\mathrm{Al}$ decreases in the $\alpha^{\prime}$ martensite [26]. Similarly, $\mathrm{Xu}$ et al. reported that during annealing, martensitic decomposition results in the segregation of $\mathrm{Al}$ in the $\alpha$ phase [27]. In contrast, Barriobero-Vila et al. argue that the overall $\mathrm{V}$ and $\mathrm{Al}$ concentration decreases in favour of Ti during the $\alpha^{\prime} \rightarrow \alpha+\beta$ transformation [28]. Furthermore, variation in phase composition has been reported to influence the lattice parameters due to differences in atomic radii [29].

Clearly, there is no overall agreement in literature on the mechanisms of martensite phase transformation, which occur during the thermal treatment of additively manufactured Ti64 alloy. The goal of this study is to investigate this mechanism by tracing the changes in crystal lattice, composition and lattice strain via in situ high temperature characterisation techniques. This should not only allow for the optimization of post-processing treatment of AM Ti64 alloy, but also provide a fundamental understanding to design new Ti-alloys for 3D-Printing.

\section{Materials \& methods}

\subsection{Sample manufacturing and preparation}

Test samples were additively manufactured using extra-low interstitial Ti64 (Grade 23, ELI-0406) powder, with particle size in the range of $10-45 \mu \mathrm{m}$. The print studies were carried out using the production scale powder bed system, Renishaw RenAM 500M equipment, which uses a $500 \mathrm{~W}$ laser with wavelength of $1070 \mathrm{~nm}$. A detailed description of the additive manufacturing process can be found in the authors' prior work [30]. Parts with dimensions $10 \times 10 \mathrm{~mm}$ were built to facilitate in situ characterisation studies (Fig. 1). These parts were built using pulse width modulation (10 milliseconds delay between exposures) with $250 \mathrm{~W}$ laser power, $100 \mu \mathrm{m}$ hatch distance according to a meander "zig-zag" scan strategy (rotated $90^{\circ}$ between each layer), 2 borders with distances of $110 \mu \mathrm{m}$, spot size of $80 \mu \mathrm{m}$, layer thickness of $30 \mu \mathrm{m}$, point distance of $50 \mu \mathrm{m}$ and with an exposure time of $90 \mu \mathrm{s}$. The delay time between each recoating of powder was $\sim 30 \mathrm{~s}$ and gas flow rate (Ar) of $\sim 29 \mathrm{~m}^{3} / \mathrm{h}$ was used during printing. The as-printed Ti64 parts were prepared by grinding and polishing, and etched using Kroll's solution ( $5 \mathrm{ml} \mathrm{HNO}, 10 \mathrm{ml} \mathrm{HF}$ (48\%), $85 \mathrm{ml}$ distilled water). Preliminary microstructure analysis of the as-built sample was performed via optical microscopy (OM) using a Digital Microscope VHX-2000 Series and Nikon Optiphot 2, and scanning electron microscopy and energy-dispersive X-ray spectroscopy (SEM/EDS) using a FEI Quanta 3D FEG Dual Beam (SEM/FIB) operating at $20 \mathrm{kV}$.

\subsection{In situ high temperature XRD analysis}

Stress relaxation and microstructure evolution analysis were carried out using in situ high temperature x-ray diffraction (XRD) measurements using a triple-axis Jordan Valley Bede D1 high resolution XRD system with $\mathrm{Cu}-\mathrm{K}_{\alpha}(\lambda=1.5405 \AA)$ radiation source operated at $45 \mathrm{kV}$ and $40 \mathrm{~mA}$. The Bede D1 system was equipped with an Anton Paar DHS 1100 heating stage which allowed in situ temperature dependent measurements in vacuum $\left(\leq 10^{-5} \mathrm{~Pa}\right)$. For XRD analysis, cross-sections of $\sim 1 \mathrm{~mm}$ from the polished surface were prepared via precision cutting using the Buehler IsoMet High Speed Pro. XRD measurements were carried out using $\theta-2 \theta$ configuration between $32^{\circ}$ and $73^{\circ}$, with a spot size of $2 \times 5 \mathrm{~mm}$ (width $\times$ length) and step size of $0.05^{\circ}$ at various temperatures starting from $25-1000^{\circ} \mathrm{C}$ using a heating rate of $200^{\circ} \mathrm{C} / \mathrm{min}$, with a dwell time of $15 \mathrm{~min}$ at each temperature before performing a scan; these take approximately $85 \mathrm{~min}$ to complete. Three samples were subjected to heat treatments at different heating temperatures and durations, as listed in Table 1. The processing of XRD data was performed using OriginPro software. Eq. (1) was used to account for the instrumental broadening, $B_{i}(0.0013 \mathrm{rad})$, when analysing the full-width at half maximum 


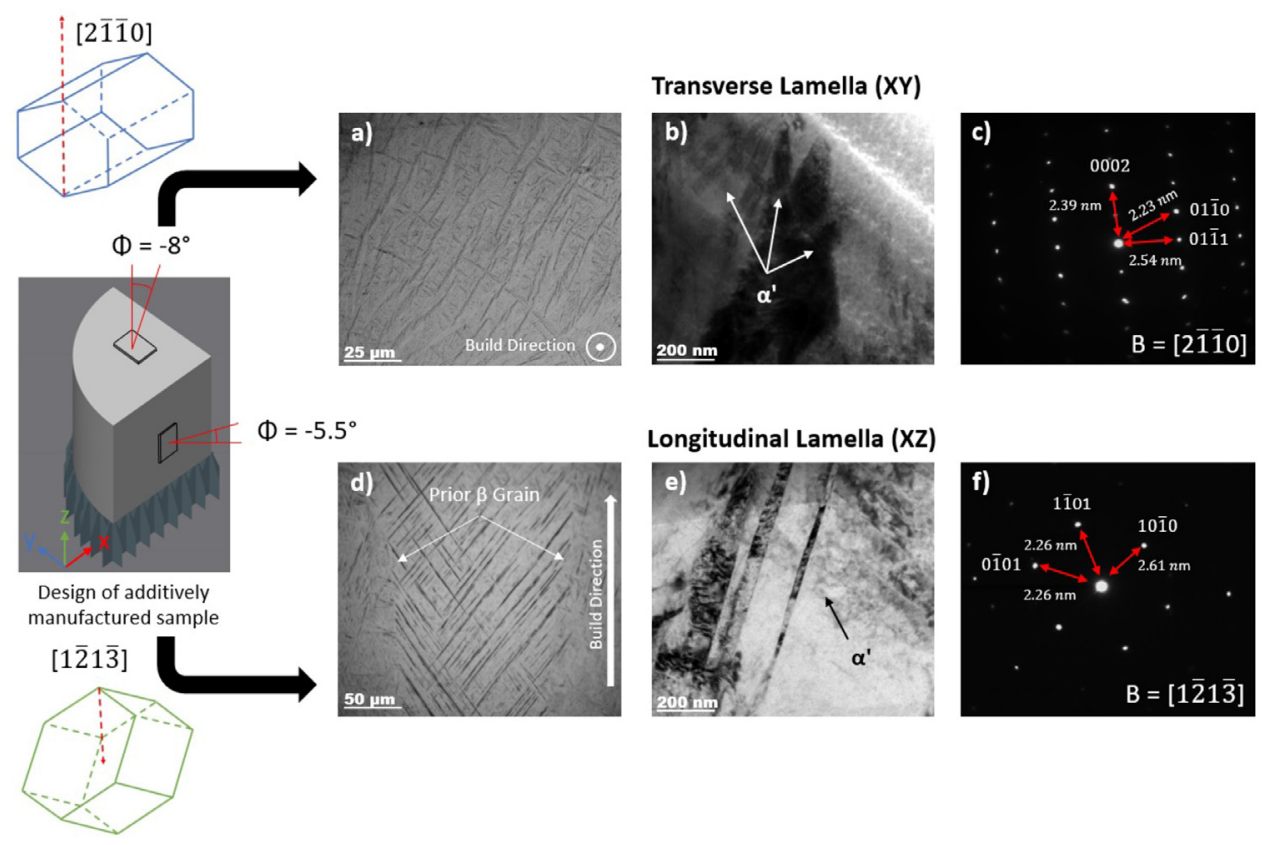

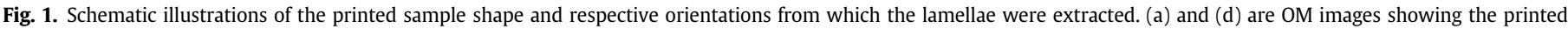

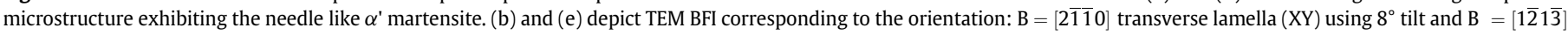
longitudinal lamella (XZ) using $-5.5^{\circ}$ tilt. (c) and (f) are the respective DPs of the transverse and longitudinal lamellae, respectively.

(FWHM) before strain analysis using Williamson-Hall method [31].

$\boldsymbol{B}_{r}=\sqrt{\left(B^{2}-B_{i}^{2}\right)}$

\subsection{In situ High temperature TEM analysis}

The micro/nano-structure evolution was investigated using an FEI Titan TEM with a 300kV acceleration voltage. For TEM analysis, thin lamellae specimens ( $70 \mathrm{~nm}$ thick) were prepared via focused ion beam (FIB) milling, mounted onto a DENS wildfire holder for in situ experiments using a MEMS based heating system with 4-point feedback controlled heating from room temperature (RT) to $900^{\circ} \mathrm{C}[32]$. Lamellae were prepared both in transverse (XY) and longitudinal (XZ) directions with respect to the build direction (Fig. 1). These two orientations were used to track the expansion mechanism in different planes. Additionally, in order to understand the effects of heat treatment on crystal lattice evolution, two different heating rates

Table 1

Heat treatment processing conditions applied to the Ti-6Al-4V samples.

\begin{tabular}{lll}
\hline Sample & Temperature $\left({ }^{\circ} \mathrm{C}\right)$ & Total annealing duration $(\mathrm{min})$ \\
\hline S1 & 25 & 100 \\
S2 & 25 & 100 \\
S3 & 25 & 100 \\
S2 & 200 & 200 \\
S1 & 300 & 200 \\
S2 & 300 & 300 \\
S2 & 400 & 400 \\
S2 & 450 & 500 \\
S2 & 500 & 600 \\
S3 & 550 & 200 \\
S1 & 600 & 300 \\
S3 & 600 & 300 \\
S1 & 650 & 400 \\
S3 & 650 & 400 \\
S3 & 700 & 500 \\
S3 & 750 & 600 \\
S1 & 1000 & 500 \\
\hline
\end{tabular}

were used during in situ TEM analysis. Heating of the longitudinal sample was performed using $100^{\circ} \mathrm{C}$ steps from $25-600^{\circ} \mathrm{C}$, and $50^{\circ} \mathrm{C}$ steps from $600-900^{\circ} \mathrm{C}$ at a rate of $100^{\circ} \mathrm{C} / \mathrm{min}$ with dwell time of 15 min at each temperature. Heating of the transverse sample was performed using rate of $200^{\circ} \mathrm{C} / \mathrm{min}$ from $25-200^{\circ} \mathrm{C}, 200-300^{\circ} \mathrm{C}$ and $400-750^{\circ} \mathrm{C}$ in $50^{\circ} \mathrm{C}$ steps with a dwell time of $60 \mathrm{~min}$ at each temperature. An area of interest was selected based on tilting the lamellae to the zone axis using the Kikuchi lines as guidelines. Once this was achieved, bright field images (BFI) and diffraction patterns (DP) were subsequently acquired after each dwell period. DPs were indexed based on the $d$-spacings, as well as angles and r-ratios between diffraction spots using the CrystalMaker and SingleCrystal software [33]. ImageJ software was used to determine the standard deviation between these spots to confirm changes observed in $d$-spacings [34]. The calibration constant $k$ was calculated using the XRD data obtained at RT [35]. In situ chemical compositional analysis was performed using EDS to acquire semi-quantitative results before heating and after imaging between $25^{\circ} \mathrm{C}$ and $600^{\circ} \mathrm{C}$ during TEM analysis of the transverse lamella (XY).

\section{Results}

Fig. 1 exhibits a schematic representation of the additively manufactured sample and the corresponding orientations of the extracted lamellae used in in situ TEM analyses. Upon inspection, the samples exhibited structural features possessing high aspect ratios scattered across the surface, which resembles needles, a characteristic of martensitic phase (Fig. 1(a) and (d)) [36]. Examination of the side view reveals long, columnar prior $\beta$-grains, which grow epitaxially along the build direction ( $\mathrm{z}$-plane). Within these $\beta$-grains, the needle-like martensitic phase grows towards the centre of the grain. The growth and orientation of these needle-like martensites can be associated with high cooling rates, resulting in erratic phase formation and growth [30]. Moreover, martensite crystal orientation appears to be dependent on the cooling path. Fig. 1 illustrates the hcp crystal orientations of martensitic phase observed for the transverse lamella (XY) (beam direction of [2 $\overline{1} \overline{1} 0]$ at $8^{\circ}$ tilt) and longitudinal lamella (XZ) (beam direction of $[1 \overline{2} 1 \overline{3}]$ at $-5.5^{\circ}$ tilt). Fig. 1 (b) and (c) illustrates the 
Table 2

Chemical composition of bulk as-built 3D printed sample.

\begin{tabular}{lc}
\hline Element & Weight $\%$ \\
\hline Ti K & $89.0 \pm 1.47$ \\
Al K & $6.3 \pm 0.37$ \\
V K & $4.7 \pm 0.58$ \\
Total & 100.00 \\
\hline
\end{tabular}

TEM BFI of the transverse (XY) lamella and the corresponding DP. The image exhibits grains with similar orientations when the beam is parallel to the [2110] direction. Similarly, Fig. 1 (d) and (e) illustrates the TEM BFI of the longitudinal (XZ) lamella and the corresponding DP, resulting in the observation of grains which followed the growth direction of the primary columnar $\beta$-grain. All grains illustrated possessed similar orientations with beam parallel to the $[1 \overline{2} 1 \overline{3}]$ direction.

The DPs were all indexed to be $h c p$, corresponding to $\alpha^{\prime}$ phase with $d$-spacings determined for the $\{10 \overline{1} 0\}$ planes in both lamellae (2.54 - $2.61 \AA)$. Consistently, XRD analysis of the as-built sample has shown that only $\alpha^{\prime}$-martensite, with $h c p$ crystal structure and lattice parameters $a=2.933$ and $c=4.655 \AA$, are present. These lattice parameters are similar to those reported by Welch et al., who acquired a martensitic structure after quenching from $950^{\circ} \mathrm{C}$ ( $a=2.931 ; c=4.681 \AA$, with $c / a=1.597$ ) [24]. Furthermore, Table 2 shows the composition of the as-built sample, which is similar to that obtained from the powder used in the manufacturing of parts, as determined by SEM/EDS analysis.

\subsection{In situ XRD analysis}

The in situ evolution of phases is shown in Fig. 2 through XRD spectra obtained in the temperature range of $25-1000^{\circ} \mathrm{C}$. At $25^{\circ} \mathrm{C}$, the XRD peaks corresponding to an imperfect crystal lattice due to peak aberrations. As stated by Ungár, these aberrations are known to cause strain and lattice defects; the most common sources of this strain include: dislocations, grain boundaries, internal stresses, chemical heterogeneities or precipitates [37]. During the analysis it was observed that the reflection peaks shifted towards lower $2 \theta$ values and became narrower with an increase in temperature, indicating an increase in crystallinity and reduction in strain. Analysis of the spectra at $500^{\circ} \mathrm{C}$ (appendix) demonstrates the onset of $\beta$ phase formation and $\alpha^{\prime}$ martensitic decomposition as the 'peak splitting' of the (0002) diffraction peak occurs; the intensities however were too small for detailed analysis. At $550^{\circ} \mathrm{C}$ a broad shoulder peak is observed at the base of the $(10 \overline{1} 1)_{\alpha / \alpha^{\prime}}$ corresponding to $(110)_{\beta}$, which confirms the start of $\alpha^{\prime}$ (martensite) $\rightarrow \alpha+\beta$ (equilibrium) phase transformation. Furthermore, the peak splitting of the (0002) peak results in two different $2 \theta$ values relatively close to one another, each belonging to the two distinctive $\alpha$ phases (Fig. 2). This splitting can be clearly seen in this figure, as the formation of a new (0002) peak between $37^{\circ}$ and $38.6^{\circ}$, hence showing the presence of both $\alpha^{\prime}$ martensitic and $\alpha$-equilibrium phases at the same time (Fig. 2). It is further observed that an increase in temperature results in a decrease in the intensity of the $\alpha^{\prime}$ peak, with a corresponding increase in the intensity of the $\alpha$-equilibrium peak. This is consistent with the continuation of phase transformation, which results in a further peak shift, with an increase in temperature.

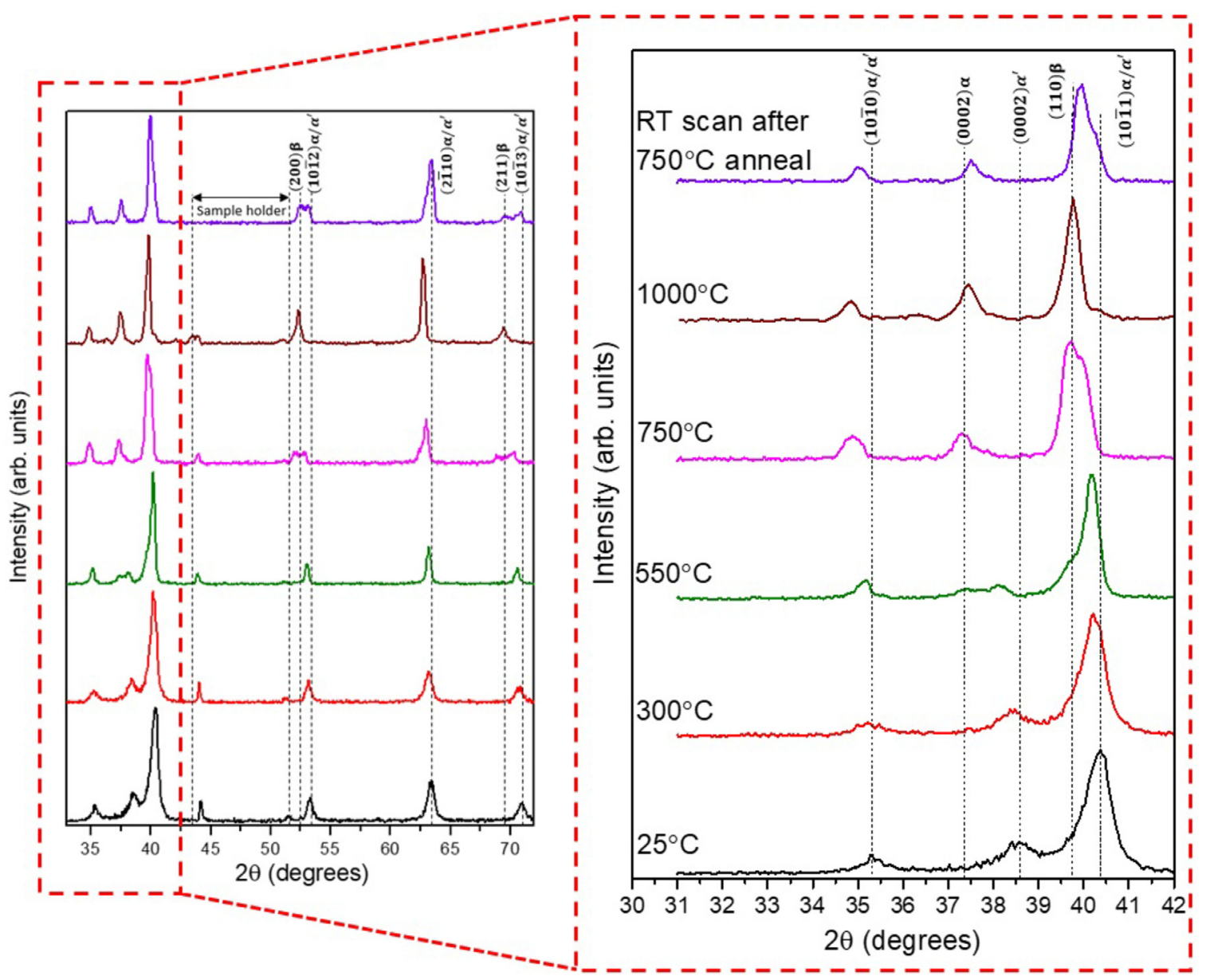

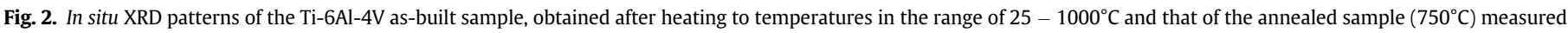
at room temperature (RT) illustrating the peak splitting and shifting phenomena and the formation of $\beta$ phase at elevated temperatures. 
Subsequently, at $750^{\circ} \mathrm{C}$, only one peak remains, corresponding to the (0002) plane, which is close to the $2 \theta$ value of $\alpha$-equilibrium. As a result, it is determined that in this annealing cycle, the martensitic phase is fully decomposed at $750^{\circ} \mathrm{C}$, hence the phase transformation $\left(\alpha^{\prime} \rightarrow \alpha+\beta\right)$ is completed. Additionally, the formation of $\beta$ peaks corresponding to the (200) and (211) planes is observed, suggesting complete phase transformation at $750^{\circ} \mathrm{C}$. Heating to $1000^{\circ} \mathrm{C}$ led to an increase in $\beta$ content, with relatively less $\alpha$-equilibrium, where the (1011), (1012) and (1013) peaks were no longer visible. The weakened intensity, but continued presence of the $\alpha$-equilibrium peaks as seen in Fig. 2., indicates that the annealing period of $1 \mathrm{hr} 40 \mathrm{~min}$ above the $\beta$ transus temperature of $995^{\circ} \mathrm{C}$ was insufficient for the full $\alpha \rightarrow \beta$ transformation in the sample.

Analysis of the S3 sample upon completion of in situ heat treatment (at $750^{\circ} \mathrm{C}$ ), followed by furnace cooling to room temperature, showed no evidence of any remaining $\alpha^{\prime}$-phase. This is most likely due to the slow cooling obtained via furnace cooling as compared with the rapid cooling found in the manufacturing process. It is interesting to highlight that the peaks observed at room temperature after heat treatment are slightly shifted to the right (higher $2 \theta$ values) when compared to the peak positions during the analyses. For example, the $(10 \overline{1} 1)$ peak obtained in the XRD pattern of the alloy after annealing coincides with the peak for the martensitic phase at $25^{\circ} \mathrm{C}$. This observation would suggest the presence of residual $\alpha^{\prime}$ martensite within the alloy, which is highly unlikely. It is important to note that the initial microstructure at $25^{\circ} \mathrm{C}$ is an imperfect crystal lattice, which results in higher $2 \theta$ values. As the sample is annealed and transformed to $\alpha+\beta$ equilibrium at $750^{\circ} \mathrm{C}$; this is unlikely to revert to the $\alpha^{\prime}$ martensite, due to the slow cooling rate used after heat treatment. In addition, the (1010) and (0002) peak positions yield $a$ and $c$ lattice parameters which do not agree with the martensitic crystal structure. Fig. 3 shows SEM images of the S3 sample after in situ XRD analysis. As observed based on XRD and SEM analyses, there is only evidence of $\alpha+\beta$ equilibrium phase after the thermal treatment. Thus, the peaks observed for the annealed sample correspond to a relaxed $\alpha+\beta$ equilibrium structure. This observation is further described in the discussion section.

The changes in lattice constants for $h c p\left(\alpha / \alpha^{\prime}\right)$ and $b c c(\beta)$ lattices with increase in temperature were determined using $2 \theta$ positions corresponding to $(10 \overline{10})_{\alpha / \alpha^{\prime}},(0002)_{\alpha / \alpha^{\prime}}$ and $(110)_{\beta}$ planes. Results show that the lattice constants $a$ and $c$ increase linearly with temperature; beyond the typical equilibrium lattice parameters for the $h c p$ crystal achieved by slow cooling $(a=2.950 \pm 0.0002 \AA$ and $c=4.683 \pm 0.0002 \AA$ ), while the $b c c$ lattice also increases but remains below the theoretical value $(a=3.19 \pm 0.001 \AA)$ [24] (appendix). Changes in lattice parameters at lower temperatures are only caused by thermal expansion of crystal lattice as it is annealed. At low temperatures, long range diffusion of elements is too slow to induce significant phase transformations; changes in lattice parameters would most likely be related to stress relaxation [18]. Fig. 3 illustrates the changes in $c / a$ ratio of the $h c p$ crystal lattice with increasing temperature. The $c / a$ ratio increases with temperature for $\alpha^{\prime}$ martensite phase until it is fully decomposed into $\alpha$-equilibrium at approximately $750^{\circ} \mathrm{C}$, where only the $a$ and $c$ lattice constants for the $\alpha$ phase can be identified. Results indicate that two critical temperature windows exist during the annealing of Ti64; (i) $25-500^{\circ} \mathrm{C}$ : the relaxation of internal residual stresses. At this temperature range no peak splitting is observed and the $c / a$ ratio does not increase significantly $(c / a=1.589-1.597)$ until there is a further increase in temperature. This result suggests that within this temperature range, the martensitic structure is maintained. Thus, changes in the XRD data can be directly associated with stress relaxation of the specimen. (ii) above $500^{\circ} \mathrm{C}$ : phase transformation occurs. It is determined that the $c / a$ ratio increases significantly as peak splitting occurs, which exclusively represents the phase transformation of the crystal lattice. When the sample is heated above the $\beta$ transus temperature of $995^{\circ} \mathrm{C}$, a decrease in the $c / a$ ratio is observed (Fig. 3). This decrease is possibly associated with the transformation of $\alpha \rightarrow \beta$ where the hcp crystal structure is transforming into $b c c$.

\subsubsection{Stress relaxation}

Gaussian-Lorentzian curve fitting was used to acquire the fullwidth half maximum (FWHM) using 5 peaks of considerable intensity to examine lattice strain evolution during heating. Fig. 5 exhibits the

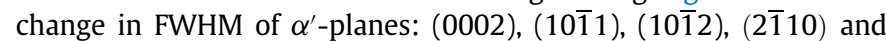
(1013) planes as a function of temperature. Examination of the changes in FWHM shows that certain planes have been strained more than others during cooling, suggesting that the initial crystal structure is composed of different crystal sizes, defects and possesses inhomogenous strain. As the temperature is increased, it is observed that the FWHM for these planes decrease considerably. This decrease indicates that the crystallinity of the alloy is improved with the removal of internal defects and relief of residual stress. Additionally, the FWHM of all planes begin to show little change at around $600^{\circ} \mathrm{C}$, suggesting that the peak broadening effect in each plane is now minimal. A point worth noting is that after peak splitting at $550^{\circ} \mathrm{C}$ (Fig. 2), the FWHM for the equilibrium $\alpha$ phase is unrepresentative of the strain reduction due to the relatively small intensity and its proximity to the dominant decomposing $\alpha^{\prime}$ martensite phase. It is reasonable to assume that at this temperature the newly formed $\alpha$-equilibrium does not result in any peak broadening effect.
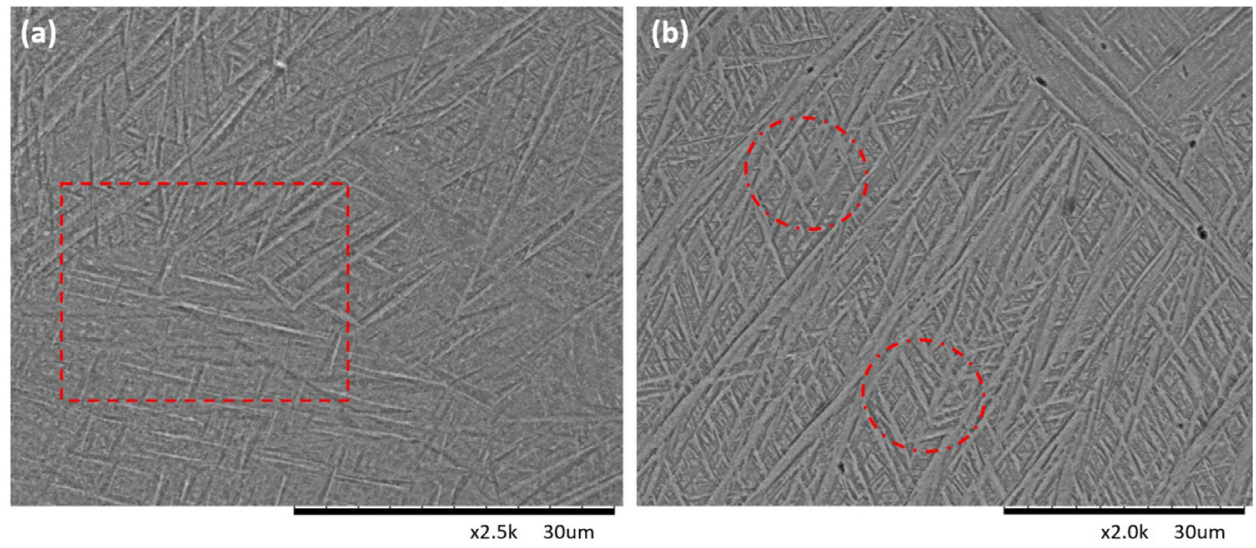

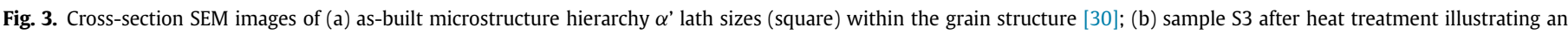
increase in basket-weave formation (circle) representative of $\alpha+\beta$ matrix. 


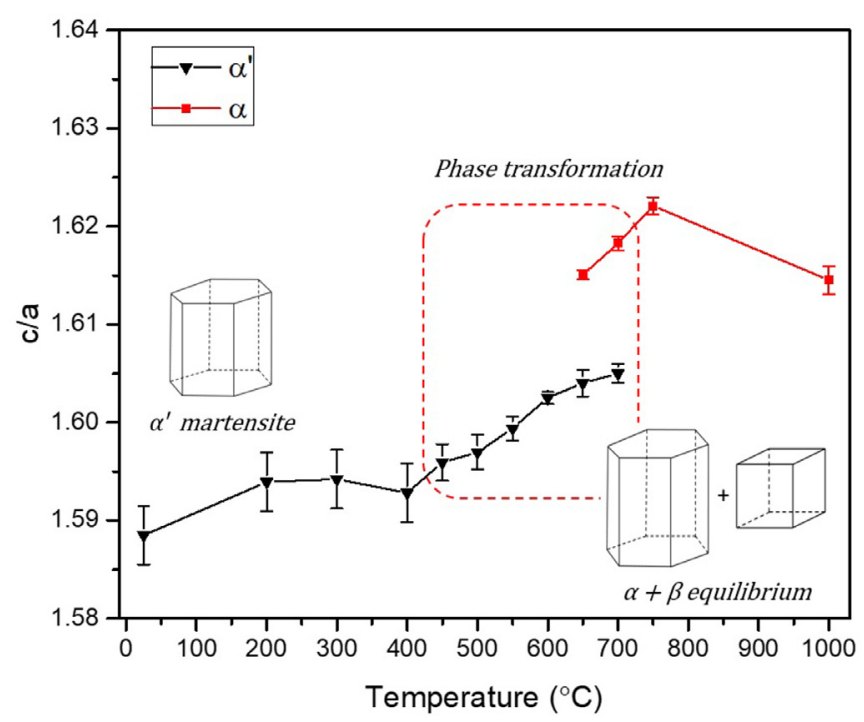

Fig. 4. Schematic of the evolution of $c / a$ ratio with increasing temperature.

The Williamson-Hall method [31] was applied to examine the degree of relaxation of the crystal lattice during heat treatment. Fig. 6 shows the microstrain evolution with increase in temperature. Based on the results and the method of manufacturing, it is observed that the initial crystal is compressed. Subsequently, heating from 25 to $300^{\circ} \mathrm{C}$ results in a small reduction in compressive strain. Above this temperature in the range $300-500^{\circ} \mathrm{C}$, the strain is no longer compressive, as it becomes slightly tensile. Up to this temperature, based on the in situ XRD data, the microstructure is still martensitic, as phase transformation has not yet begun. Treatment above $500^{\circ} \mathrm{C}$ showed that the strain decreased to near-zero strain, indicating the completion of stress/strain relaxation at this temperature. Furthermore, the tensile strain observed during heating is relatively small when compared to the original compressive strain of $0.37 \pm 0.12 \%$. Thus, it is reasonable to correlate strain change to the increase in $c / a$ ratio as shown in Fig. 4.

\subsection{In situ TEM analysis}

\subsubsection{Transverse lamella $(X Y)$}

Analysis of the transverse lamella specimen at RT facilitated the

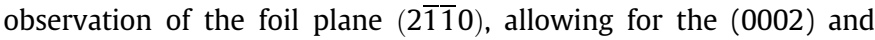

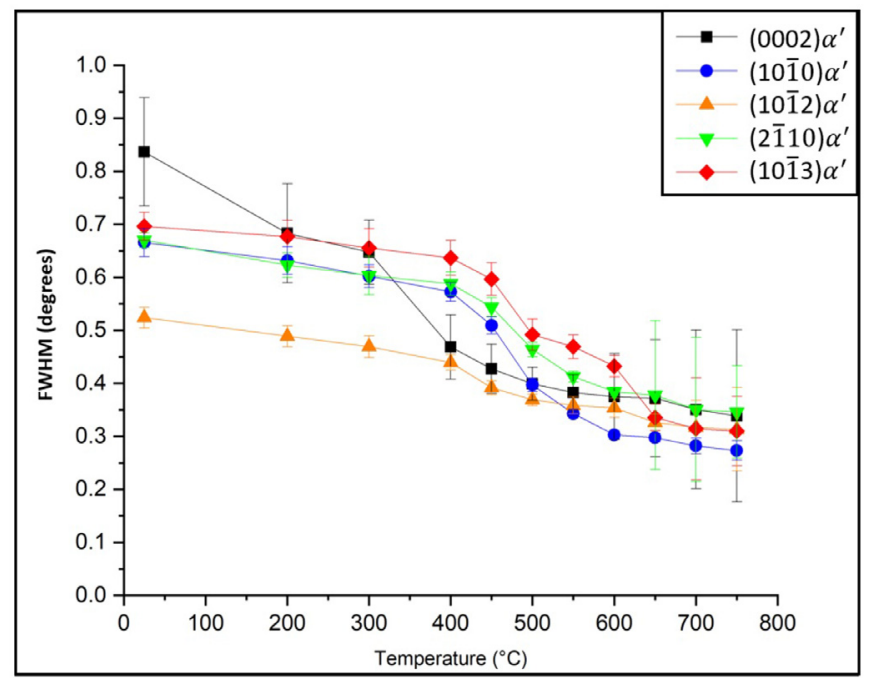

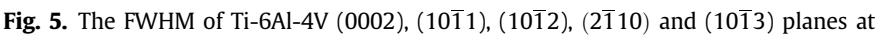
various temperatures obtained from XRD patterns.

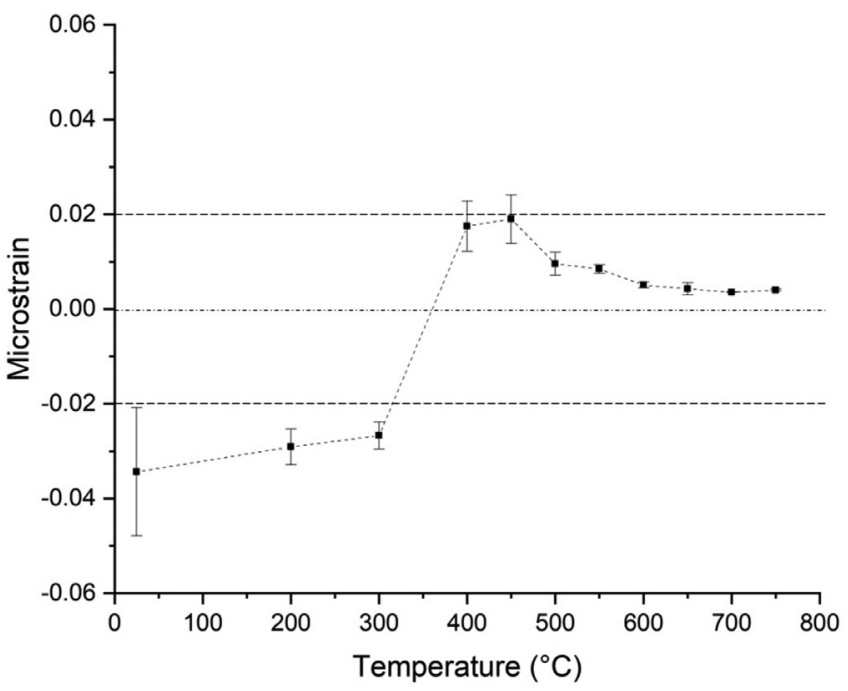

Fig. 6. Evolution of microstrain within the crystal lattice with increase in temperature.

(1010) planes to be indexed in the $h c p$ crystal. The grain morphology of the sample is shown in Fig. 7 (a) - (c) as it is heated from $25^{\circ} \mathrm{C}$ to $550^{\circ} \mathrm{C}$ and $600^{\circ} \mathrm{C}$. Fig. 7 (d) - (f) illustrates the relative changes in $d$-spacings as the lamella is heated between these temperatures. It is observed based on the analysis of DPs that the crystal structure changes with an increase in temperature. The $d$-spacing of the (0002) plane increased from 2.39, 2.40 and $2.42 \mathrm{~nm}$, as the temperature was increased from $25^{\circ} \mathrm{C}$ to $550^{\circ} \mathrm{C}$ and $600^{\circ} \mathrm{C}$, respectively. Similarly, it was observed that the $d$-spacing of the $(01 \overline{1} 0)$ increased from $2.54 \mathrm{~nm}$ to $2.56 \mathrm{~nm}$ and remained at $2.56 \mathrm{~nm}$ for diffraction spectra obtained at $25^{\circ} \mathrm{C}, 550^{\circ} \mathrm{C}$ and $600^{\circ} \mathrm{C}$, respectively. Fig. 7 illustrates the overall changes in lattice parameters ( $a$ and $c$ ) between 25 to $750^{\circ} \mathrm{C}$ according to the heating rate used during analysis of the specimen. No evident for changes in grain morphology were observed during heating. Based on these observations, it is evident that the crystal lattice expands exponentially in the transverse lamella (Fig. 8).

\subsubsection{Longitudinal lamella (XZ)}

It was observed upon in situ heating of the longitudinal lamella from 25 to $600^{\circ} \mathrm{C}$, that the grain morphologies became distorted with both a narrowing and thickening of the original boundaries, resulting in DPs which could not be indexed properly. This change in grain morphology is associated with fringe movement and self-accommodation due to the expansion and contraction of the crystal lattice as observed in Fig. 9(a)-(c). Thermal stabilisation at $650^{\circ} \mathrm{C}$ allowed the re-observation of the $h c p$-phase $\left(\alpha^{\prime}\right)$ present at RT with the same crystal orientation. Interestingly, a stepwise expansion in the hcp lattice of a single $\alpha$-grain was determined by analysing the changes in $d$-spacings of the $(10 \overline{1} 0)$ and $(0 \overline{1} 11)$ planes, with increasing temperature as shown in Fig. 9(e). On further increasing the temperature to $700^{\circ} \mathrm{C}$, the symmetry of the $h c p$ lattice is restored (Fig. 9(f)). This stepwise expansion suggests that the mechanism of expansion is an intricate process, where the $h c p$ crystal lattice becomes asymmetrical as $\alpha^{\prime}$ and $\alpha$ phase coexist during dissolution of the $\alpha^{\prime}$ martensite phase. Arising from this observation, a possible mechanism for crystal transformation is discussed in detail later in this paper. At $700^{\circ} \mathrm{C}$, twinning became evident in the DP (Fig. 9(f)). Further increasing the temperature to between 750 and $900^{\circ} \mathrm{C}$ gave rise to no further significant changes in $d$-spacings, hence lattice parameters remained the same.

In situ heating of the lamellae specimens showed that a stepwise expansion of the crystal lattice occurs with an increase in temperature. However, it is worth noting that the annealing period of the two lamellae were not the same, resulting in slightly different rate of change, and values of $a$ and $c$ parameters as the temperature is 

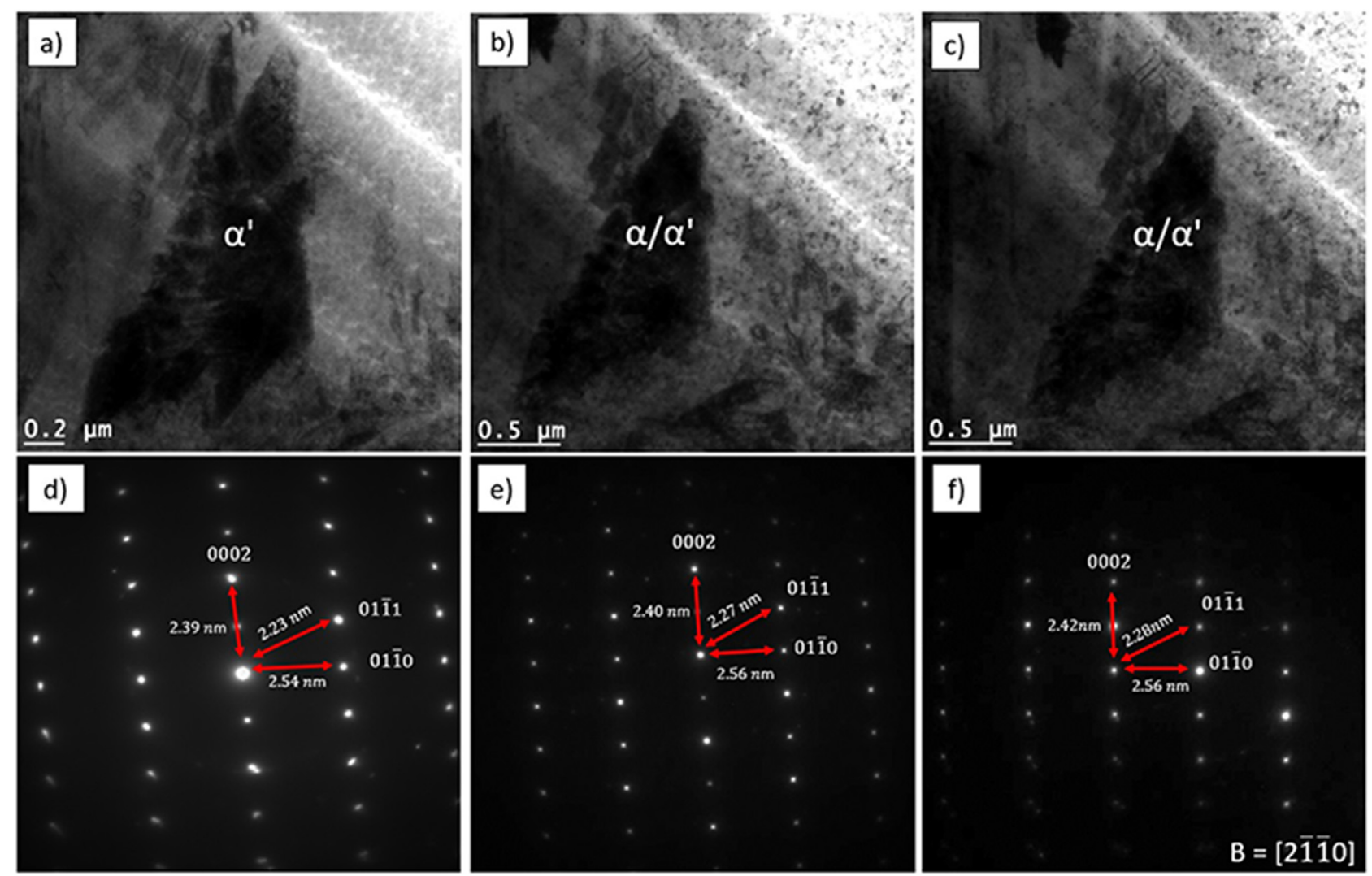

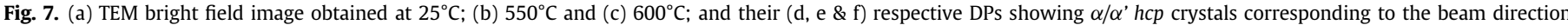
$\mathrm{B}=[2 \overline{1} \overline{1} 0]$; illustrating changes in $d$-spacings due to heating of specimen.

increased. In addition, observations made during in situ TEM analysis above RT are consistent with those obtained based on XRD measurements. The increase in $a$ and $c$ parameters is associated with thermal expansion of the crystal lattice, where the $a$ and $c$ lattice parameters in both lamellae exceed the theoretical lattice parameters for $\alpha$ equilibrium $(a=2.950 ; c=4.683 \AA$ ) [24], reaching values of 2.966 and $4.814 \AA$ in the transverse lamella, respectively. Expansion beyond the equilibrium values is most likely due to the saturation of titanium within the crystal lattice during heating, which is discussed in the next section. Furthermore, the formation of $\beta$ phase was not evident in the HR-TEM experiments, possibly due to the restricted sample area $(\sim 70 \mathrm{~nm})$. A likely explanation is that the lamellae were cut from

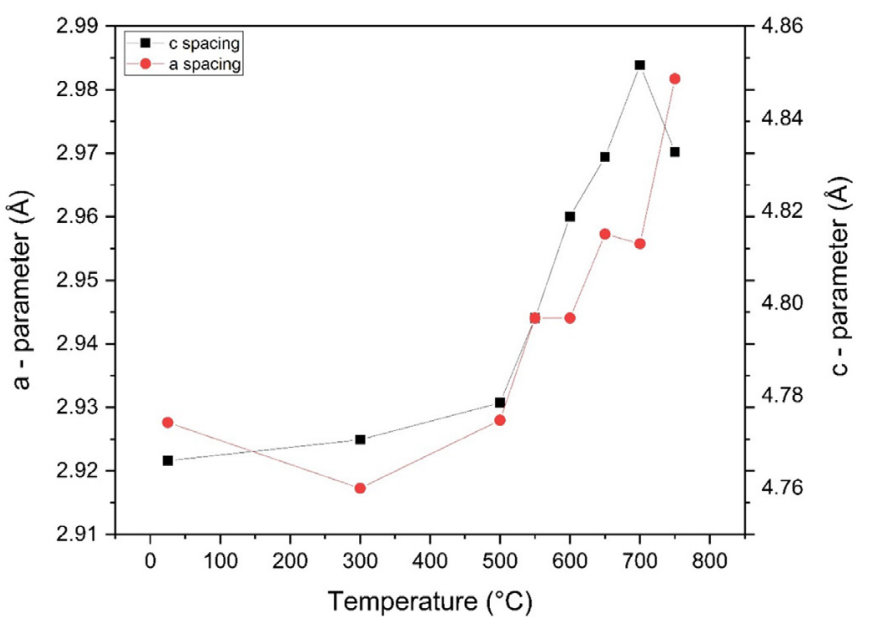

Fig. 8. Changes observed for the $a$ and $c$ parameters for the transverse specimen with increasing temperature. within a large primary grain $(200 \mu \mathrm{m})$, such as the one illustrated in Fig. 1(d). Subsequently, formation of $\beta$ phase was not observed possibly due to the lack of $\beta$-particles which form inside the $\alpha$-laths during heating [38].

\subsection{In situ EDS analysis}

Fig. 10 illustrates the changes in the concentration of $\mathrm{V}$ and $\mathrm{Al}$ within the Ti matrix of the Ti64, obtained for the three regions of interest in the transverse lamella (1,2 and 3). These three regions exhibit the same crystal orientation (approximately $500 \mathrm{~nm}$ apart), during heating from 25 to $600^{\circ} \mathrm{C}$. As shown in this figure, at $25^{\circ} \mathrm{C}$ some variation in chemical composition was obtained between the three regions of interest, hence $\alpha^{\prime}$ martensitic grains even with similar lattice parameters exhibit some variation in chemical composition (Fig. 10). These differences can be used to qualitatively define the different chemical compositions of the $\alpha^{\prime}$ martensitic grains and the diffusion of elements between grains as $\alpha^{\prime}$ martensite decomposes into $\alpha$ equilibrium during annealing. Region 1 represents high concentration of $\mathrm{Al}$; Region 2 represents a chemical composition similar to the powder $(\sim 6 \% \mathrm{Al}$ and $\sim 4 \% \mathrm{~V})$; Region 3 represents high concentration of $\mathrm{V}$. Therefore it can be assumed that thermal cycling by successive layer deposition during additive manufacturing, causes elemental segregation which results in compressed-asymmetrical crystals, exhibiting high lattice strain. Yang et al. observed that thermal cycling has a direct impact on the final microstructure of parts and can cause the build-up of internal stresses [39]. This observation is further supported by Ungár, who highlighted that chemical heterogeneities or precipitates are the most common sources of strain in the crystal lattice [37]. At $300^{\circ} \mathrm{C}$, Al concentration decreases substantially in Region 1, while increasing in both Regions 2 and 3; V concentration follows a similar but inverted trend, increasing for both Region 1 and 2 whilst it decreases considerably from $\sim 9 \%$ to $7 \%$ in Region 3 . 

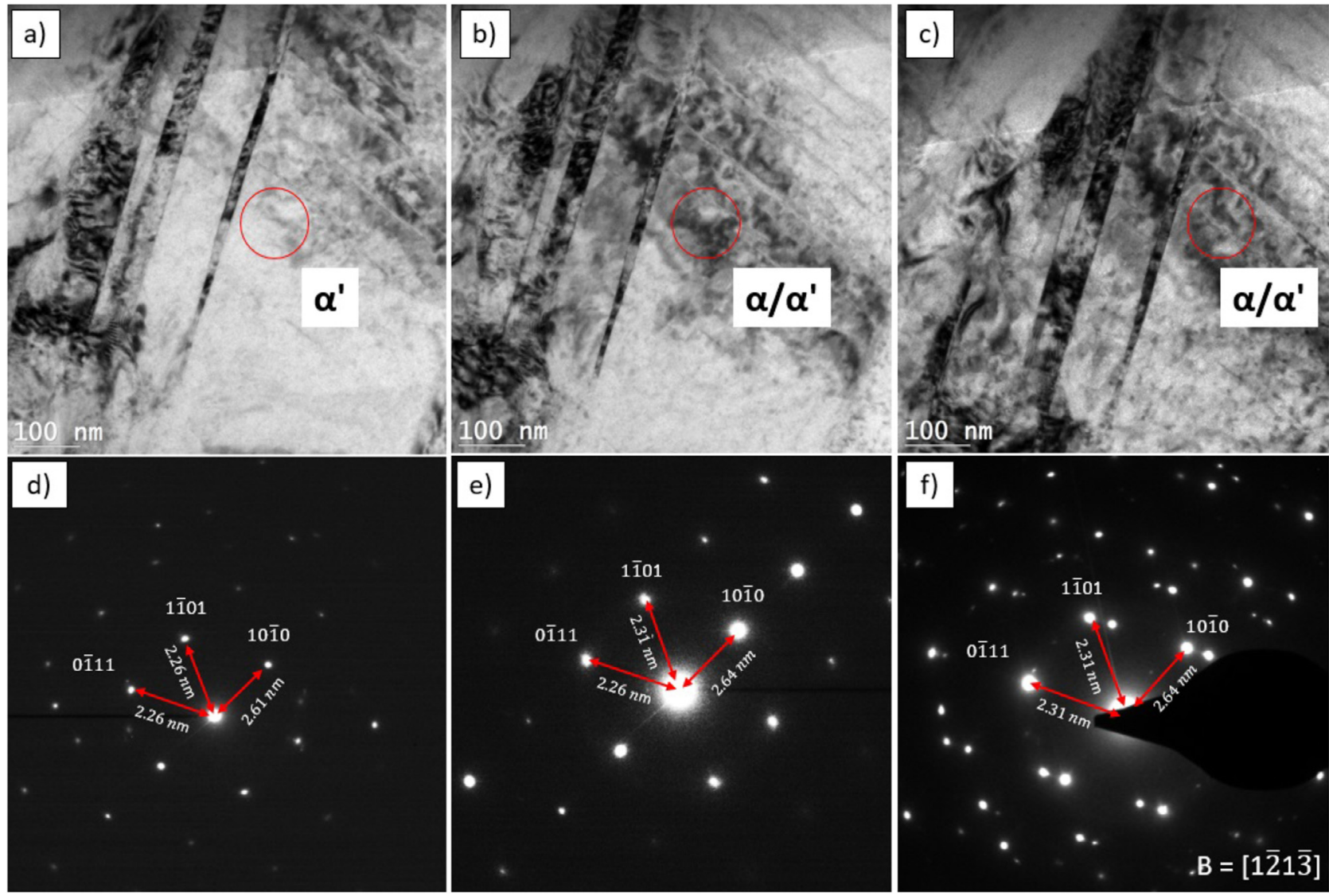

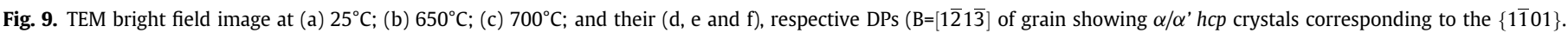
Changes in $d$-spacings due to heating of specimen and formation of annealing twins at $700^{\circ} \mathrm{C}$ can be seen.

Thus, when the temperature is increased to $300^{\circ} \mathrm{C}$, Al and $\mathrm{V}$ atoms within the crystal lattice gain sufficient energy to diffuse and accommodate within the crystal lattice, in order to relieve the internal residual stresses. This result is consistent with the results obtained from XRD analysis, which showed that stress relaxation occurred on heating from 25 to $500^{\circ} \mathrm{C}$. Furthermore, at $500^{\circ} \mathrm{C}, \mathrm{V}$ concentration decreases for all three regions; Al concentration also decreases for Region 2 and 3 but increases for Region 1 . When the temperature is increased to $550^{\circ} \mathrm{C}$, all regions experience a decrease in $\mathrm{Al}$ concentration, $\mathrm{V}$ concentration decreases in Region 1 and increases in Regions 2. It is further observed that Region 3 attains equilibrium at $550^{\circ} \mathrm{C}$ and exhibits the 'ideal' chemical composition of $6 \% \mathrm{Al}$ and $4 \% \mathrm{~V}$. Once the temperature is increased to $600^{\circ} \mathrm{C}$, both alloying elements decrease in concentration in all regions, to $4.6 \%$ and $2.4 \%$, respectively. It is reported that a decrease in $\mathrm{V}$ content occurs in primary $\alpha^{\prime}$ grain with the formation of the $\beta$ phase at $600^{\circ} \mathrm{C}$ since $\mathrm{V}$ is a $\beta$ stabilising element [40]. However, in this study it was not possible to observe any $\beta$ formation within the regions of interest. Therefore, the decrease of $\mathrm{V}$ is indicative of the formation of a $\beta$ phase proximal to the area of analysis. Additionally, the decrease in Al content represents the formation of $\alpha$ equilibrium, as $\mathrm{Al}$ is an $\alpha$ stabilising element. This observation is consistent with the XRD spectra results, which also showed formation of the $\alpha$ phase at this temperature.

\section{Discussion}

In situ experiments up to $1000^{\circ} \mathrm{C}$ have demonstrated that there is a stepwise expansion of the Ti64 lattice, with an accompanied relief of internal residual stress and decomposition of $\alpha^{\prime}$ (martensite) $\rightarrow \alpha+\beta$ (equilibrium). It is known that materials used in layer-bylayer deposition are subjected to cyclic heating and cooling which results in a primarily martensitic microstructure [4]. Comparatively, the cooling rate between selected laser melting (SLM) and traditional strategies such as water quenching and work hardening are very different; SLM produces a cooling rate of $\sim 10^{3}-10^{8} \mathrm{~K} / \mathrm{s}$ [4], while water quenching produces a cooling rate close to $1500 \mathrm{~K} / \mathrm{s}$ [39]. As a result, the microstructure produced is primarily martensitic. Martensite possesses the morphology of a compressed version of a $h c p$ lattice, which is obtained as a result of rapid cooling rates. While the theoretical lattice parameters for $\alpha$-equilibrium are $a=2.935 \AA$ and $c=4.685$ $\AA$ [ 24], XRD analysis results showed that the initial martensitic crystal structure possesses lattice parameters of $a=2.933 \AA$ and $c=4.655 \AA$ corresponding to $(0 \overline{1} 01)$ and $(0 \overline{1} 11)$ planes, respectively. Comparing these values, it is clear that both $\alpha^{\prime}$ martensite and equilibrium $\alpha$ possess very similar lattice parameters, however the $\alpha^{\prime}$ martensite phase is a somewhat smaller, compressed lattice structure.

Changes due to heating in the Ti64 crystal lattice structure were monitored using XRD. With the increase in the $d$-spacing values, there is an associated narrowing of the diffraction peaks, as well as evidence for diffusion of atoms within the crystal matrix. In this section these changes are discussed such that the stepwise stress relaxation and phase evolution are detailed, and a mechanism of crystal transformation is proposed within the Ti64 alloy.

\subsection{Lattice strain evolution}

Based on XRD results, when the temperature is increased peaks of interest shift towards a lower $2 \theta$ value and become narrower. These two phenomena have independent effects on the crystal lattice making it difficult to attribute changes in peak position and morphology to specific events. The physics behind the crystallite size-related peak broadening in XRD, involves averages of several crystallite 

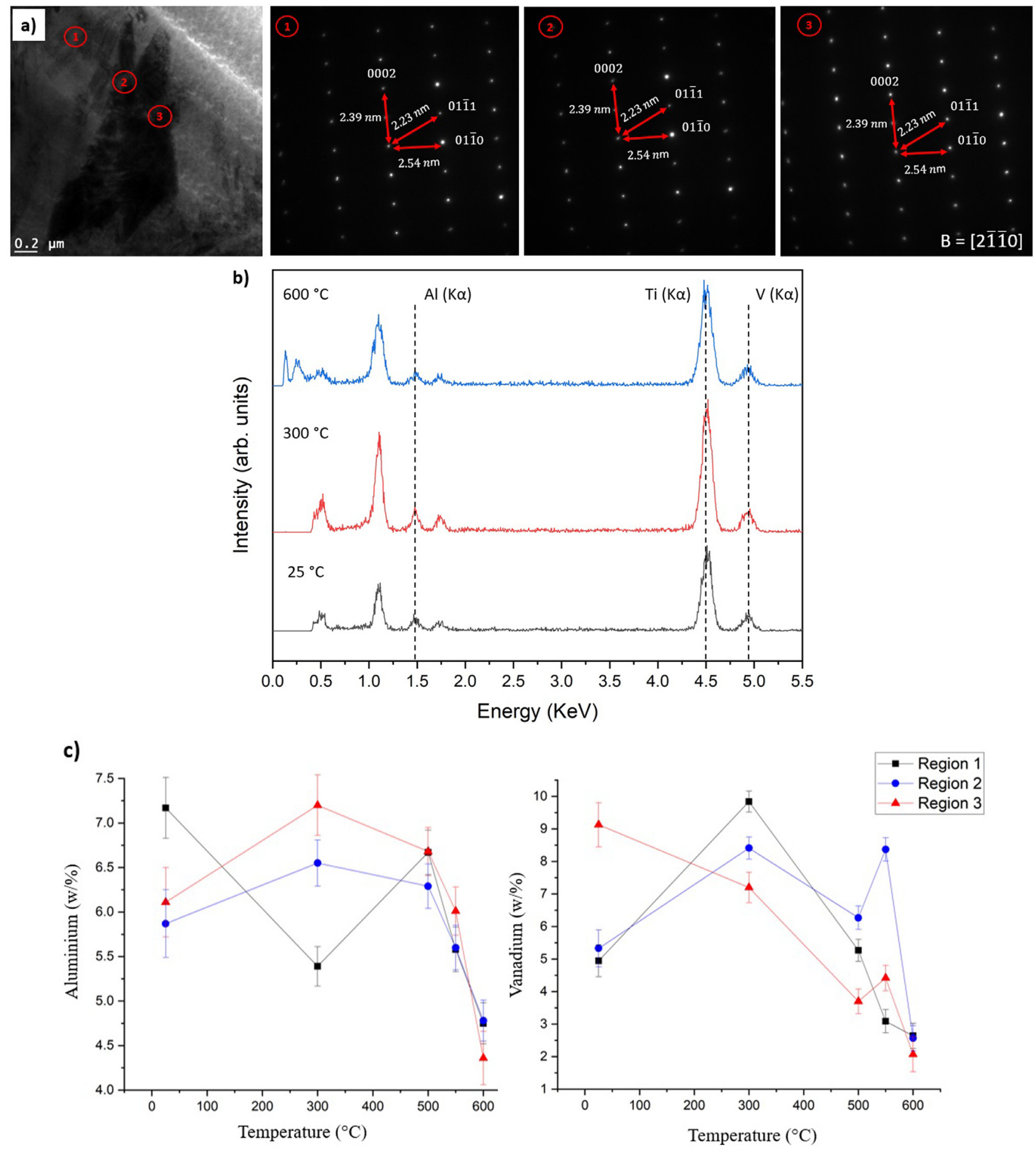

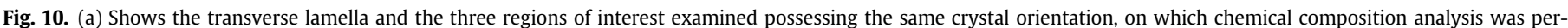

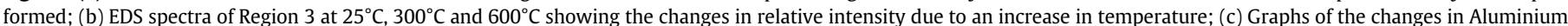
and Vanadium within the Titanium matrix obtained for the three regions exhibiting changes in chemical composition with increase in heat treatment temperature.

dimensions, shapes, etc. In essence, the crystallite induced size broadening is proportional to $1 / \cos (\theta)$. Similarly, peak broadening can be caused by strain, more precisely micro-strain. Micro-strain occurs primarily due to crystal defects, inducing local deviation of the $d$-spacings, thereby giving some broadening. As a result, the $d$-spacing will increase or decrease slightly around a nominal value due to these local crystal plane deviations. Typically, the integrated peak broadening for this effect is proportional to $\tan (\theta)$. For these micro-strains, the general compressive/tensile forces tend to balance each other such that only peak broadening is present. Macro- strain on the other hand is a directed strain which results in a peak shift, as opposed to peak broadening. Similarly, lattice expansion will also contribute to peak shifting, i.e. larger $d$-spacing leading to smaller $\theta$, via Bragg's law. In this study, the changes in peak position and morphology observed are analysed, such that delimitation between stress relaxation and phase transformation can be made. The shift in XRD peak $d$-spacing upon heating is likely to be due to the reduction of internal residual stresses on increasing the temperature from $25^{\circ} \mathrm{C}$ to $400^{\circ} \mathrm{C}$, as well as lattice expansion on heating from $25^{\circ} \mathrm{C}$ to $1000^{\circ} \mathrm{C}$. Peak broadening can be attributed to the 
internal residual stress of the crystal structure mentioned previously [27]. Yang et al. reported that both peak broadening of the $(10 \overline{1} 0)_{\alpha}$ and $(0002)_{\alpha}$ in $\mathrm{Ti}$, as well as higher $2 \theta$ values occur due to the presence of $\alpha^{\prime}$ martensite with slightly different lattice parameters to the equilibrium $\alpha$ phase [38]. In addition, Ungár highlighted that higher $2 \theta$ values are commonly associated to residual stresses [36]. It is therefore concluded that the initial shift towards a lower $2 \theta$ value and the narrowing of the peaks are primarily related to the relief of internal residual stress within the crystal lattice and not associated with lattice expansion.

The microstrain is calculated from the slope acquired by plotting the FWHM with respect to their peak angles; a negative slope indicating the presence of compressive strain [41], while a positive slope corresponds to the presence of tensile strain in the material [42]. Hence, as the crystal lattice expands, a tensile strain occurs due to expansion of lattice spacings. Nishikawa et al. observed a similar result in their study where the $\mathrm{CeO}_{2} / \mathrm{Si}$ interface was under tensile strain due to the expansion of the lattice spacing in $\mathrm{CeO}_{2}$ [43]. The increase in c/a ratio determined in this study, from 1.588 to 1.597 , is therefore related to lattice strain relaxation. For this reason, it is possible to define the lattice parameters of an unstrained martensitic crystal structure approximately as $a=2.945 \AA$ and $c=4.703 \AA$ with $c / a$ ratio of 1.597 . To the authors knowledge there have been no previous reports on how heat treatment influences the lattice parameters or $c / a$ ratio of an unstrained martensitic crystals.

\subsection{Crystal lattice evolution}

Thermal treatment of the Ti64 alloy at $550^{\circ} \mathrm{C}$ resulted in the formation of the $\beta$ phase $(110)_{\beta}$, relative shifts of the (1010), (0002) and (11) 101$)$ peaks, and peak splitting of the (0002) plane indicating that phase transformation has initiated. In contrast, Xu et al. reported that near-complete martensite decomposition can be achieved at a temperature as low as $400^{\circ} \mathrm{C}$ [44].

This observation suggests that even though phase transformation may begin at a temperature as low as $400^{\circ} \mathrm{C}$, the rate of microstructural evolution is dependent on the rate of martensitic decomposition such that enough stabilizing elements, $\mathrm{Al}$ and $\mathrm{V}$, have diffused out of the lattice structure for the formation of $\alpha$ and $\beta$ phase, respectively. A subsequent increase in temperature results in the higher rate of martensitic dissolution, as well as crystal lattice expansion. De Formanoir et al., for example, reported that complete decomposition of the martensite occurs at $700^{\circ} \mathrm{C}$, even when short annealing times are applied [25]. In this study, the full decomposition of $\alpha^{\prime}$ martensite was found to occur after annealing at $750^{\circ} \mathrm{C}$, resulting in a $c / a$ ratio of 1.622. In contrast, $\mathrm{Xu}$ et al. observed complete decomposition after annealing at $800^{\circ} \mathrm{C}$, with the ratio of $\alpha$ close to $1.590-1.600$ [27] Furthermore, the residual $\alpha$ phase observed during analysis at $1000^{\circ}$ $\mathrm{C}$ may indicate that the $\beta$ transus temperature of the PBF-LB parts may be higher than that of cast Ti64 $\left(995^{\circ} \mathrm{C}\right)$. Vracken et al. reported a similar observation, where the reference material being examined did not fully transform to $\beta$ phase after annealing at $1015^{\circ} \mathrm{C}[20]$.

Based on the in situ HT-TEM analysis of the longitudinal and transverse lamellae, significant disparities between the lattice expansion processes were observed. In the case of the longitudinal lamella obtained in the $(\mathrm{XZ})$ direction, the expansion process was inhomogenous. The latter, obtained in the $(\mathrm{XY})$ direction, expanded homogeneously. This is probably due to the different heat treatment cycles used during in situ TEM experiments (specified in the experimental section) and the limitations of the technique itself as only a small number of grains can be studied. A possible explanation for the observed expansion mechanism is the much lower heating rate used in the analysis of the longitudinal lamella $(\mathrm{XZ})$, with a longer dwell time than that of the transverse lamella (XY), which emulated the XRD heating rate. As a result, during imaging, the crystal lattice transformed in an intrinsic manner, resulting in two different $c$ parameters for the $(0 \overline{1} 11)$ and (1101), suggesting that the crystal lattice is distorted with $\alpha$ and $\alpha^{\prime}$ coexisting during transformation. Furthermore, the $c$-parameters calculated for the (0002) and (1011) planes during XRD and TEM analysis of both lamellae are only congruent at temperatures above $700^{\circ} \mathrm{C}$. These results suggest that the crystal lattice expands unsymmetrically where different $c$-parameters can be observed for a single $h c p$ crystal at lower temperatures (Fig. 7(e) $\&(\mathrm{f})$ ). At temperatures above $700^{\circ} \mathrm{C}$, the fully expanded lattice possesses $a$ and $c$ lattice parameters corresponding to an equilibrium $\alpha$ crystal. Elmer et al. reported a similar finding in their studies where they observed a slight expansion of the $\alpha$ lattice parameters during heating [29]. A possible explanation for the distortion in the hcp crystal can be the stepwise diffusion of $\mathrm{Al}$ and $\mathrm{V}$ atoms causing asymmetry in the crystal lattice during phase transformation. This is consistent with in situ elemental analysis results, where different areas of the same grain vary in composition. Again, these results suggest that $\alpha^{\prime}$ martensite and $\alpha$-equilibrium can coexist within the same crystal lattice resulting in a distorted $h c p$ crystal. This observation agrees with in situ HT-XRD analysis where peak splitting was observed at $550^{\circ} \mathrm{C}$ and the (0002) peaks became less evident while the $(10 \overline{1} 0)_{\alpha / \alpha^{\prime}}$ displayed a higher intensity at $750^{\circ} \mathrm{C}$ (Fig. 2). The relative ratios and peak position suggest that equilibrium $\alpha$ and martensitic $\alpha^{\prime}$ can coexist; while $\alpha^{\prime}$ slowly transforms with increasing temperature into equilibrium $\alpha$, which possesses a preferred grain orientation in the $(10 \overline{1} 0)_{\alpha / \alpha^{\prime}}$ plane direction. This suggests that over time, the ratio of $\alpha / \alpha^{\prime}$ will increase until the crystal structure is fully $\alpha+\beta$. De Formanoir et al. observed a similar result in their studies, where the (0002) and (1012) peaks in their duplex annealed specimen 'split', which is given as the evidence for the coexistence of $\alpha$ and $\alpha^{\prime}$ martensite phases at RT [25].

\subsection{Evolution in chemical compositional}

During crystallographic analysis, the most noticeable development is the relative increase in $a$ and $c$ parameters when the temperature is increased above $500^{\circ} \mathrm{C}$ (Fig. 10). This expansion, however, is attributed to the relative changes in elemental concentration within the crystal lattice, as observed via in situ TEM / EDS. As a result, it was determined that both $\mathrm{Al}$ and $\mathrm{V}$ content decrease in concentration relative to Ti, at temperatures above $500^{\circ} \mathrm{C}$. This result suggests that during martensitic decomposition, both alloying elements are susceptible to diffuse out of the grain as the new phases form. This finding is in contrast to previous studies which stated that during martensitic decomposition $\mathrm{Al}$ progressively segregates into the $\alpha^{\prime}$ martensite lamellae, while $\mathrm{V}$ is being rejected to the small $\beta$ grains surrounding these lamellae [43]. Similarly, Zhang et al. proposes that for the $\beta$ phase to form, the $\beta$ stabilising $\mathrm{V}$ needs to diffuse out of the primary grain and form on the grain boundary [13]. Furthermore, Elmer et al. monitored the changes in $\alpha$ and $\beta$ phases as a function of heating. In their studies they observed that partitioning of $\mathrm{V}$ causes changes in lattice parameters of the $\beta$ phase [29]. This is in agreement with the changes found in lattice parameters of the $\beta$ phase in this study; as the $\mathrm{V}$ concentration reduces, the formation of the $\beta$ phase is evident, and with further diffusion a relative increase in lattice parameter is observed at $600^{\circ} \mathrm{C}$.

\subsection{The proposed mechanism of crystal transformation}

The proposed mechanism of stress relaxation and phase transformation of a single $\alpha^{\prime}$ martensite phase in additively manufactured Ti64 samples during in situ annealing is shown schematically in Fig. 11. In this figure the initial compressed martensitic-hcp crystal with hypothetical composition of Ti64 is illustrated with Ti atoms in orange, $\mathrm{Al}$ in yellow and $\mathrm{V}$ in grey. As demonstrated based on the XRD results, upon heating from 25 to $400^{\circ} \mathrm{C}$, the $a$ and $c$ lattice parameters increase slightly. This increase is associated with the internal diffusion and self-accommodation of the alloying elements $\mathrm{Al}$ and $\mathrm{V}$ within the crystal lattice, as observed through the variation in elemental composition during EDS analysis within the same grains, 
$\mathrm{Ti}-147 \mathrm{pm}$

b)

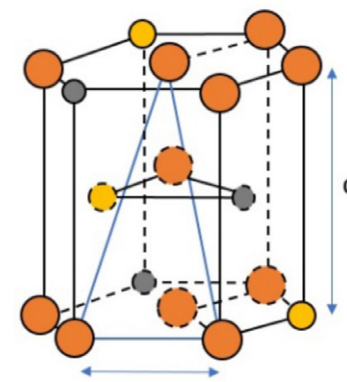

a

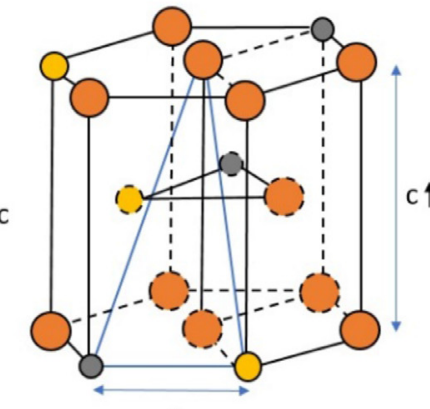

$\mathrm{a} \uparrow$ c)

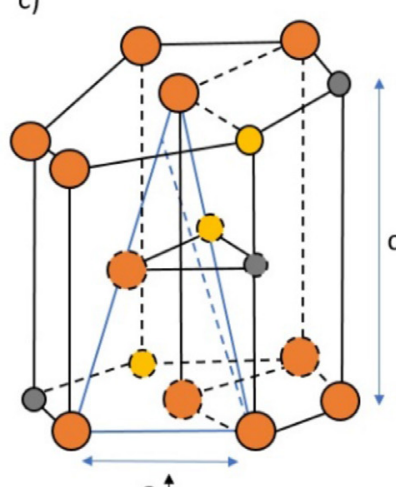

$\mathrm{a} \uparrow$ d)<smiles>C1CCC1</smiles>

$\alpha^{\prime}$ martensite
at $25^{\circ} \mathrm{C}$

$\alpha^{\prime}$ martensite at $400{ }^{\circ} \mathrm{C}$ $\alpha^{\prime} / \alpha$ coexisting
at $\sim 550^{\circ} \mathrm{C}$

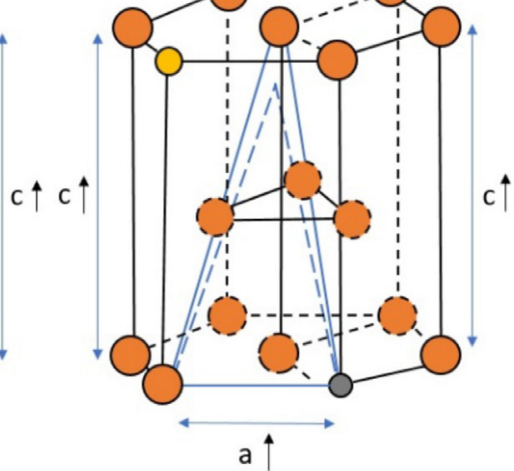

$\alpha$ equilibrium at $700^{\circ} \mathrm{C}$

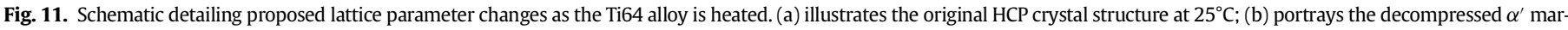

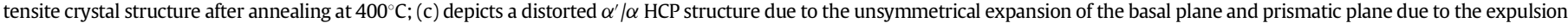

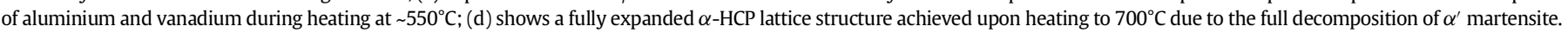

resulting in an unstrained martensitic phase. Heating above $400^{\circ} \mathrm{C}$ results in a linear increase in lattice parameters where the alloying elements, $\mathrm{V}$ in particular, begin to diffuse out of the grain as $\alpha^{\prime}$ martensite decomposes to form $\alpha$ and $\beta$ phases at approximately $550^{\circ} \mathrm{C}$. The diffusion of such atoms of atomic radii $143 \mathrm{pm}(\mathrm{Al})$ and $135 \mathrm{pm}$ (V) along with their substitution by a Ti atom (147 pm), results in an increase in crystal lattice size [45]. This results in an unsymmetrical $h c p$ crystal which occurs due to the varying chemical compositions throughout the lattice chain, causing the basal and prismatic planes to increase independently of one another. Higher treatment temperatures result in an increase in the rate of diffusion of $\mathrm{Al}$ and $\mathrm{V}$ [28]. Subsequently, the crystal lattice becomes saturated in Ti, which further expands due to the element's largest atomic size. This expansion provides sufficient room within the crystal lattice, allowing elements to rearrange and accommodate to form $\alpha+\beta$ equilibrium as $\alpha^{\prime}$ martensite fully decomposes. It was observed that above $700^{\circ} \mathrm{C}$, thermal expansion causes the crystal lattice to expand beyond the theoretical and annealed $\alpha+\beta$ equilibrium lattice size [34]. Therefore, annealing above $700^{\circ} \mathrm{C}$, whilst below the $\beta$ transus temperature of $\left(995^{\circ} \mathrm{C}\right)$, increases the rate of martensitic decomposition through facilitating the diffusion of alloying elements, with the associated expansion of the crystal lattice. Once the martensitic phase is fully decomposed and annealing is complete, the sample is cooled to RT resulting in $\alpha+\beta$ equilibrium phase with lattice parameters: $a=2.955 \AA$ and $c=4.789 \AA$ for $\alpha$-phase with $c / a$ ratio for a $h c p$ structure 1.621 , and $a=3.191 \AA$ for the $\beta$-phase. This $c / a$ ratio is similar to that reported by Halevy et al. for high purity Ti obtained via Rietveld analysis (1.622) [46]. An alternative explanation for the increase in crystal lattice size at high temperatures is the oxidation of the specimen, which is known to cause an increase in lattice parameters [47].

\section{Conclusion}

In this study the mechanism of stress relaxation and phase transformation of Ti64 alloy fabricated using additive manufacturing, was observed by high temperature in situ XRD and TEM analyses. Based on experimental results it was observed that stress relaxation of the crystal lattice occurs as the alloy is heated from 25 to $400^{\circ} \mathrm{C}$, without any evidence of phase transformation. Above $400^{\circ} \mathrm{C}, \alpha^{\prime}$ (martensite) $\rightarrow \alpha+\beta$ (equilibrium) phase transformation was determined to occur in a stepwise manner. The XRD and TEM results both indicate that the crystal structure is transformed, while $\alpha$ (equilibrium) and $\alpha^{\prime}$ (martensite) coexist during this transformation as $\alpha^{\prime}$ martensite gradually decomposes. More specifically, the different heating rates used in the in situ TEM analysis showed a direct influence on the expansion mechanism of the crystal lattice. The lower heating rate sample $\left(100^{\circ} \mathrm{C} / \mathrm{min}\right)$ showed a stepwise expansion, possibly due to the additional time given at the specific transition temperatures during heating. Whilst this type of mechanism was not observed in the sample annealed at the higher heating rate $\left(200^{\circ} \mathrm{C} / \mathrm{min}\right)$. Furthermore, it was observed that the $a$ and $c$ lattice parameters of the $h c p$ crystal increased linearly between 500 $700^{\circ} \mathrm{C}$ causing the crystal structure to fully transform in to $\alpha+\beta$ equilibrium at $700^{\circ} \mathrm{C}$. Heating above this temperature caused a further increase of the $a$ and $c$ parameters, while maintaining the $c / a$ ratio, as a result of thermal expansion of the crystal lattice.

For the first time, a mechanism of phase transformation is proposed, which occurs via the substitution of $\mathrm{Al}, \mathrm{V}$ and $\mathrm{Ti}$ atoms from the crystal lattice due to thermal heating as determined through concentration changes during heat treatment in combination with the stepwise evolution, which is consistent with HT-XRD and HT-TEM measurements. Further work is necessary to correlate changes in lattice parameters to mechanical properties of parts to determine the effect of different $\alpha^{\prime} / \alpha+\beta$ ratios have on part performance.

\section{Declaration of Competing Interest}

The authors declare that they have no known competing financial interests or personal relationships that could have appeared to influence the work reported in this paper.

\section{Acknowledgment}

This publication was supported in part by Science Foundation Ireland (SFI) through the I-Form Advanced Manufacturing Research Centre, (Grant Number 16/RC/3872). All TEM imaging and analysis including EDS was carried out at the Advanced Microscopy Laboratory (AML) at the AMBER centre, CRANN Institute, Trinity College Dublin, Ireland. The AML is an SFI supported imaging and analysis centre. VN would also wishes to acknowledge the European Research Council (CoG 3D2D Print) and Science Foundation Ireland (I-Form, AMBER, PIYRA, US-Ireland) for funding. The authors would also like to acknowledge the assistance of Croom Precision Medical. 
Table 3

Lattice parameters at room temperature for wrought Ti64 and 3D printed Ti64 parts during $\left(25-1000^{\circ} \mathrm{C}\right)$ and after $\left(750^{\circ}\right.$ C) annealing

\begin{tabular}{llllllll}
\hline & temp & a_mean & a_SD & c_mean & c_SD & c/a (mean) & absolute error (c/a) \\
\hline$\alpha$ [Malinov, S., et al.] & 25 & 2.935 & & 4.673 & & 1.592 & \\
$\alpha^{\prime}$ & 25 & 2.933 & 0.003 & 4.659 & 0.003 & 1.588476 & 0.003 \\
$\alpha^{\prime}$ & 200 & 2.928 & 0.003 & 4.667 & 0.003 & 1.593921 & 0.003 \\
$\alpha^{\prime}$ & 300 & 2.935 & 0.003 & 4.679 & 0.003 & 1.594208 & 0.003 \\
$\alpha^{\prime}$ & 400 & 2.942 & 0.003 & 4.686 & 0.0035 & 1.592794 & 0.003 \\
$\alpha^{\prime}$ & 450 & 2.94 & 0.0025 & 4.692 & 0.0015 & 1.595918 & 0.002 \\
$\alpha^{\prime}$ & 500 & 2.945 & 0.002 & 4.703 & 0.002 & 1.596944 & 0.002 \\
$\alpha^{\prime}$ & 550 & 2.948 & 0.001 & 4.715 & 0.002 & 1.599389 & 0.001 \\
$\alpha^{\prime}$ & 600 & 2.951 & 0.0005 & 4.729 & 0.001 & 1.602508 & 0.001 \\
$\alpha^{\prime}$ & 650 & 2.95 & 0.001 & 4.731 & 0.0005 & 1.603729 & 0.001 \\
$\alpha$ & 650 & 2.977 & 0.0005 & 4.808 & 0.0005 & 1.615049 & 0.000 \\
$\alpha^{\prime}$ & 700 & 2.954 & 0.001 & 4.741 & 0.0005 & 1.604942 & 0.001 \\
$\alpha$ & 700 & 2.976 & 0.001 & 4.816 & 0.0005 & 1.61828 & 0.001 \\
$\alpha$ & 750 & 2.969 & 0.001 & 4.816 & 0.001 & 1.622095 & 0.001 \\
$\alpha$ & 1000 & 2.973 & 0.002 & 4.8 & 0.001 & 1.614531 & 0.001 \\
$\alpha$ & & & & & & & \\
& Annealed & 2.955 & 0.001 & 4.789 & 0.002 & 1.620643 & 0.001 \\
\hline
\end{tabular}

\section{Appendix}

Appendix Table 3 - Malinov, S., Sha, W., Guo, Z., Tang, C.C. and Long, A.E., 2002. Synchrotron X-ray diffraction study of the phase transformations in titanium alloys. Materials Characterization, 48(4), pp. 27 +09-295.

\section{Reference}

[1] D. Thomas, Costs, benefits, and adoption of additive manufacturing: a supply chain perspective, Int. J. Adv. Manufactur. Technol. 85 (5-8) (2016) 1857-1876.

[2] W. Toh, P. Wang, X. Tan, M. Nai, E. Liu, S. Tor, Microstructure and wear properties of electron beam melted Ti-6Al-4V parts: A comparison study against as-cast form, Metals 6 (11) (2016) 284.

[3] S. Liu, Y.C. Shin, Additive manufacturing of Ti6Al4V alloy: A review, Mater. Des. 164 (2019) 107-552.

[4] L.E. Loh, C.K. Chua, W.Y. Yeong, J. Song, M. Mapar, S.L. Sing, Z.H. Liu, D.Q. Zhang, Numerical investigation and an effective modelling on the Selective Laser Melting (SLM) process with aluminium alloy 6061, Int. J. Heat Mass Trans. 80 (2015) 288-300.

[5] M. Žitňanský, L. Čaplovič, Effect of the thermomechanical treatment on the structure of titanium alloy Ti6Al4V, J. Mater. Process. Technol. 157 (2004) 643-649.

[6] A. Dehghan-Manshadi, M.H. Reid, R.J. Dippenaar, Effect of microstructural morphology on the mechanical properties of titanium alloys, J. Phys. Confer. Ser. 240 (1) (2010) 012022 IOP Publishing.

[7] Y. Liu, Y. Yang, D. Wang, A study on the residual stress during selective laser melting (SLM) of metallic powder, Int. J. Adv. Manuf. Technol. 87 (1-4) (2016) 647-656.

[8] H. Galarraga, R.J. Warren, D.A. Lados, R.R. Dehoff, M.M. Kirka, P. Nandwana, Effects of heat treatments on microstructure and properties of Ti-6Al-4V ELI alloy fabricated by electron beam melting (EBM), Mater. Sci. Eng. A 685 (2017) 417-428.

[9] H. Ali, H. Ghadbeigi, K. Mumtaz, Processing Parameter effects on residual stress and mechanical properties of selective laser melted Ti6Al4V, J. Mater. Eng. Perform. 27 (8) (2018) 4059-4068.

[10] A.H. Nickel, D.M. Barnett, F.B. Prinz, Thermal stresses and deposition patterns in layered manufacturing, Mater. Sci. Eng. A 317 (1-2)(2001) 59-64.

[11] I. Van Zyl, I. Yadroitsava, I. Yadroitsev, Residual stresses in direct metal laser sintered parts, Interim Interdiscipl. J. 14 (1) (2015) 110-123

[12] L. Van Belle, G. Vansteenkiste, J.C. Boyer, Investigation of residual stresses induced during the selective laser melting process, Key Eng. Mater. (Vol 554 (2013) 1828 1834 Trans Tech Publications.

[13] X.Y. Zhang, G. Fang, S. Leeflang, A.J. Böttger, A.A. Zadpoor, J. Zhou, Effect of subtransus heat treatment on the microstructure and mechanical properties of additively manufactured Ti-6Al-4V alloy, J. Alloys Compoun. 735 (2018) 1562-1575.

[14] M.J. Donachie, Titanium: A Technical Guide, ASM international, 2000.

[15] DIN 65083, (Entwurf). Luft- und Raumfahrt - Wärmebehandlung von Gussstücken aus Titan und Titanlegierungen, Berlin: Beuth, Nov. 2011.

[16] DIN 17869, Werkstoffeigenschaften von Titan und Titanlegierungen - Zusätzliche Angaben, Berlin: Beuth, Juni 1992.

[17] E. Uhlmann, R. Kersting, T.B. Klein, M.F. Cruz, A.V. Borille, Additive manufacturing of titanium alloy for aircraft components, Procedia Cirp 35 (2015) 55-60.

[18] J.W. Elmer, T.A. Palmer, S.S. Babu, E.D. Specht, Low temperature relaxation of residual stress in Ti-6Al-4V, Scripta Mater. 52 (10)(2005) 1051-1056.

[19] Combres, Y., 2013. Traitements thermiques des alliages de titane. https://scholar google.com/scholar?hl=en\&as_sdt=0\%2C5\&q=Combres\%2C+Y.\%2C+2013.+Traitements+thermiques+des+alliages+de+titane \&btnG $=$.
[20] B. Vrancken, L. Thijs, J.P. Kruth, J. Van Humbeeck, Heat treatment of Ti6Al4V produced by selective laser melting: microstructure and mechanical properties, J. Alloys Compou. 541 (2012) 177-185.

[21] V Vilaro, Colin T., C., J.D. Bartout, As-fabricated and heat-treated microstructures of the Ti-6Al-4V alloy processed by selective laser melting, Metallurg. Mater. Trans. A 42 (10) (2011) 3190-3199.

[22] Ter Haar, G., T. Becker, Selective laser melting produced Ti-6Al-4V: post-process heat treatments to achieve superior tensile properties, Materials 11 (1) (2018) 146.

[23] R. Pederson, Microstructure and Phase transformation of Ti-6Al-4V (Doctoral dissertation, Luleå tekniska Universitet (2002)

[24] G. Welsch, R. Boyer, E.W.eds. Collings, Materials Properties Handbook: Titanium Alloys, ASM international, 1993.

[25] C. De Formanoir, G. Martin, F. Prima, S.Y. Allain, T. Dessolier, F. Sun, S. Vives, B. Hary, Y. Bréchet, S. Godet, Micromechanical behavior and thermal stability of a dual-phase $\alpha+\alpha$ 'titanium alloy produced by additive manufacturing, Acta Mater. 162 (2019) 149-162.

[26] H. Matsumoto, H. Yoneda, K. Sato, S. Kurosu, E. Maire, D. Fabregue, T.J. Konno, A. Chiba, Room-temperature ductility of Ti-6Al-4V alloy with $\alpha^{\prime}$ martensite microstructure, Mater. Sci. Eng. A 528 (3) (2011) 1512-1520.

[27] W. Xu, E.W. Lui, A. Pateras, M. Oian, M. Brandt, In situ tailoring microstructure in additively manufactured Ti-6Al-4V for superior mechanical performance, Acta Mater. 125 (2017) 390-400.

[28] P. Barriobero-Vila, G. Requena, T. Buslaps, M. Alfeld, U. Boesenberg, Role of element partitioning on the $\alpha-\beta$ phase transformation kinetics of a bi-modal Ti-6Al-6V-2Sn alloy during continuous heating, J. Alloys Compd. 626 (2015) 330-339.

[29] J.W. Elmer, T.A. Palmer, S.S. Babu, E.D. Specht, In situ observations of lattice expansion and transformation rates of $\alpha$ and $\beta$ phases in Ti-6Al-4V, Mater. Sci. Eng. A 391 (1-2) (2005) 104-113.

[30] F.R. Kaschel, M. Celikin, D.P. Dowling, Effects of Laser Power on Geometry, Microstructure and Mechanical Properties of Printed Ti-6Al-4V Parts, J. Mater. Process. Technol. (2019) 116-539.

[31] A.K. Zak, W.A. Majid, M.E. Abrishami, R. Yousefi, X-ray analysis of ZnO nanoparticles by Williamson-Hall and size-strain plot methods, Solid State Sci. 13 (1) (2011) 251-256

[32] M. Canavan, D. Daly, A. Rummel, E.K. McCarthy, C. McAuley, V. Nicolosi, Novel insitu lamella fabrication technique for in-situ TEM, Ultramicroscopy 190 (2018) 21-29.

[33] D.C. Palmer, CrystalMaker, CrystalMaker Software Ltd, Begbroke, Oxfordshire, England, 2014.

[34] Rasband, W.S., Image J, U.S.National Institutes of Health, Bethesda, Maryland, USA, https://imagej.nih.gov/ij/, 1997-2018.

[35] A.R. Ghasemi, F. Taheri-Behrooz, M.M. Shokrieh, Measuring residual stresses in composite materials using the simulated hole-drilling method, Residual Stresses Composite Mater. (2014) 76-120 Woodhead Publishing.

[36] V Vilaro, Colin T., C., J.D. Bartout, As-fabricated and heat-treated microstructures of the Ti-6Al-4V alloy processed by selective laser melting, Metallurg. Mater. Trans. A 42 (10) (2011) 3190-3199.

[37] T. Ungár, Microstructural parameters from X-ray diffraction peak broadening, Scr. Mater. 51 (8) (2004) 777-781.

[38] H. Ali, L. Ma, H. Ghadbeigi, K. Mumtaz, In-situ residual stress reduction, martensitic decomposition and mechanical properties enhancement through high temperature powder bed pre-heating of Selective Laser Melted Ti6Al4V, Mater. Sci. Eng. A 695 (2017) 211-220.

[39] J. Yang, H. Yu, J. Yin, M. Gao, Z. Wang, X. Zeng, "Formation and control of martensite in Ti-6Al-4V alloy produced by selective laser melting", Mater. Design 108 (2016) 308-318. 
[40] S.Q. Wu, Y.J. Lu, Y.L. Gan, T.T. Huang, C.Q. Zhao, J.J. Lin, S. Guo, J.X. Lin, Microstructural evolution and microhardness of a selective-laser-melted Ti-6Al-4V alloy after post heat treatments, J. Alloys Compd. 672 (2016) 643-652.

[41] R. Sivakami, S. Dhanuskodi, R. Karvembu, "Estimation of lattice strain in nanocrystalline RuO 2 by Williamson-Hall and size-strain plot methods", Spectrochim. Acta Part A 152 (2016) 43-50.

[42] V. Senthilkumar, P. Vickraman, M. Jayachandran, C. Sanjeeviraja, Structural and electrical studies of nano structured $\mathrm{Sn} 1-\mathrm{x} \mathrm{Sb}$ x $\mathrm{O} 2(x=0.0,1,2.5,4.5$ and 7 at\%) prepared by co-precipitation method, J. Mater. Sci. Mater. Electron. 21 (4) (2010) 343-348.

[43] Y. Nishikawa, D. Matsushita, N. Satou, M. Yoshiki, T. Schimizu, T. Yamaguchi, H. Satake, N. Fukushima, Tensile strain in Si due to expansion of lattice spacings in CeO2 epitaxially grown on Si (111), J. Electrochem. Soc. 151 (9) (2004) F202-F205.
[44] W. Xu, M. Brandt, S. Sun, J. Elambasseril, Q. Liu, K. Latham, K. Xia, M. Qian, Additive manufacturing of strong and ductile $\mathrm{Ti}-6 \mathrm{Al}-4 \mathrm{~V}$ by selective laser melting via in situ martensite decomposition, Acta Mater. 85 (2015) 74-84.

[45] J.C. Slater, “Atomic Radii in Crystals", J. Chem. Phys. 41 (10) (1964) 3199-3205 Bibcode:1964JChPh..41.3199S, doi: 10.1063/1.1725697.

[46] I. Halevy, G. Zamir, M. Winterrose, G. Sanjit, C.R. Grandini, A. Moreno-Gobbi, Crystallographic structure of Ti-6Al-4V, Ti-HP and Ti-CP under high-pressure, J. Phys. Conf. Ser. 215 (1) (2010) 012013 IOP Publishing.

[47] J.M. Oh, B.G. Lee, S.W. Cho, S.W. Lee, G.S. Choi, J.W. Lim, Oxygen effects on the mechanical properties and lattice strain of Ti and Ti-6Al-4V, Met. Mater. Int. 17 (5) (2011) 733-736. 